\title{
Erosion Wear Analysis of Coated and Uncoated Ductile Materials at Different Velocities and Angles
}

\author{
Ashraya Gautam ${ }^{1}$, Charanjit Singh Sandhu ${ }^{2,}$ Harpreet $\operatorname{singh}^{3}$, Navjot singh ${ }^{4}$ \\ ${ }^{1,3}$ Mechanical Engineering Department, Rayat And Bahra Engineering College Mohali-140104, India \\ ${ }^{2}$ Mechanical Engineering Department, SUSCET Tangori -140306, India \\ ${ }^{4}$ Mechanical Engineering Department,sukhmani dera bassi India
}

\begin{abstract}
Wear is the gradual, layer-by-layer destruction of the surface of metallic materials by mechanical action of erodents,or passage of slurry. The wear of metals occurs upon the frictional rubbing of surfaces, wear, and cavitations, as well as upon the action of strong gas or liquid currents upon a surface, especially at high temperatures and pressures. Various parts of jet engines, nuclear reactors, and steam turbines boilers and pipes in the thermal power plants and cement industries where the pipe carries the slurry were subjected to destruction by erosion. Increased resistance of parts against erosion can be achieved by improving process technology or unit design and by selecting more suitable material; heat treatment also increases resistance against erosion. Structural materials have been developed that provide durable operation of parts under erosive conditions, such as some niobium and molybdenum alloys. In the present work the effect of erosion wear on $18 \mathrm{Cr} 8 \mathrm{Ni}$ based steel strip coated with Epoxy polyester and powder coating has been investigated experimentally. Comparison of the erosion resistance and loss of metal for different mass flow rate and angle's are done.
\end{abstract}

Keywords: Erosion wear, 18Cr8Ni,Epoxy coatings.

\section{INTRODUCTION}

The removal of material from the surface of a ductile metal by small impacting particles is a design consideration. Erosion wear is a process of progressive removal of material from the surface ductile material due to repeated impacts of solid particles. The particles suspended in the flow of solid liquid mixture erode the surface in contact with it. There by limiting the service life of equipment used for slurry transportation system. Erosion wear caused by the kinetic energy transferred to target surface by impinging solid particles. Higher the loss of material for higher kinetic energy of the impinging particle. So impact velocity largely affects the erosion wear of target material. Also erosion wear depends on the impact angle, slurry concentration, size of erodent, its shape etc Erosion wear can be classified into three categories solid particle erosion, liquid impact erosion and cavitations erosion. Solid particle erosion is the loss of material volume from target material due to continues impingement of solid particles present in the flowing fluid. The continues striking of liquid jet on material surface cause liquid impact erosion. The deformation and removal of material from target surface due to repeated nucleation, growth and sudden collapse of bubbles is known as cavitation.

\section{Epoxy Polyester ,Powder Coating}

Limited availability of time for the maintenance or the replacement of the piping system in the industries have emphasized on the need for the better coatings..In a day to day working operational processes in different conditions tend erode the internal surface of pipes [1].So, problem lies. on Erosion wear and emphasized on the material which are largely used in the industries like thermal power plants, cement industries and the textile mills where generally hot stream of air, slurries and the ash particles were transported through these pipes and during this process they largely suffers the internal wear which further enhances the possibility of formation of micro level cracks with the passage of time and gradients like temperature and pressurized jet of stream and of sediments may some time causes sudden leakages or failure of the pipes.[2] Various experimentation work has been conducted with different coatings the machine parts like turbines where direct contact of the jet with the blade. Major problem in the piping system faces is the costlier coating processes.[3]Epoxy powder coating shows the improved erosion resistance. Based on review of the reported research work, the attempt has been made to investigate ant find the better and economical coating over the conventional coatings

\section{Experimental Set Up}

A. Dimensions and material of construction of Erosion Wear tester.The effective area of specimen is $55 \mathrm{mmX} 50 \mathrm{~mm}$ 


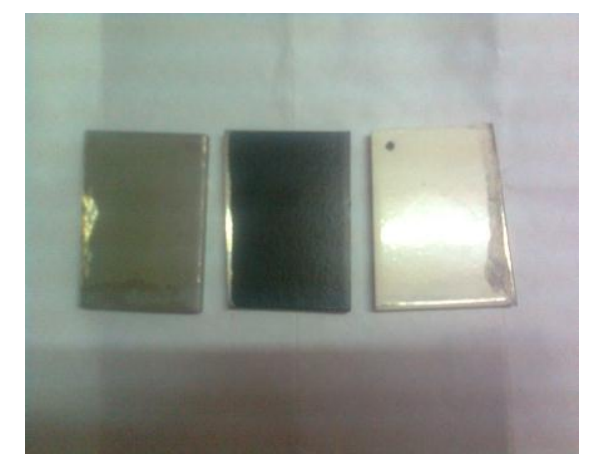

Fig. 1: Actual viw of the specimens

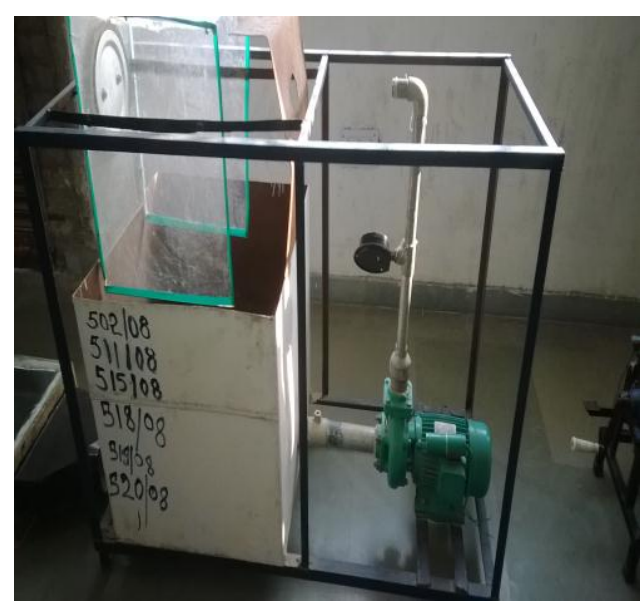

\section{B. Material used}

Fig.2 Actual view of the set up

18Cr8Ni steel srtps were purchased Aggarwal Metal pvt ltd.The specifications are:

Particle shape:Rectangular

Hardness: 540VHN

Chromium: 18.090

Nickel:8.010

Carbon:0.0516

Magnese:0.84

Phosphorous:0.034

Fe:72.69

\section{Preparation of Epoxy powder and polyester coatings.}

Firstly the wight $18 \mathrm{Cr} 8 \mathrm{Ni}$ specimen is calculated for epoxy Polyester and powder coating.

\section{Properties of Epoxy polyester-}

Table 2 -Properties of Epoxy Polyester

\begin{tabular}{|l|l|}
\hline Powder Size $(\mu \mathrm{m}$ & $-45+22$ \\
\hline Apparent Density & 1.8 \\
\hline Coating Thickness $(\mu \mathrm{m}$ & $200 \pm 10$ \\
\hline Hardness $\left(\mathrm{Kg} / \mathrm{mm}^{2}\right.$ & 1150 \\
\hline Compressive Strength $(\mathrm{MPa}$ & 2000 \\
\hline
\end{tabular}

Properties of Epoxy Powder Coating

Table-3 Properties of Epoxy Powder

\begin{tabular}{|l|l|}
\hline Powder Size $(\mu \mathrm{m}$ & $-35+22$ \\
\hline Specific Gravity & 5.22 \\
\hline Coating Thickness $(\mu \mathrm{m}$ & $200 \pm 10$ \\
\hline Hardness ( Kg/mm & ( 1320 \\
\hline Compressive Strength $(\mathrm{MPa}$ & 2200 \\
\hline
\end{tabular}




\section{Experimental procedure}

The schematic of the experiment is shown in Fig.2.The Erosion testing machine was experimentally at Baddi University,India .The flow rate of the slurry or sediments is conrtolled through the stop valve.The veocity meter is set up to measure the velocity of the pumped slurryand can be regulated through stop valve.Metallic tank is being used to collect and reuse the slurry. Various results in the graphical form were plotted between cummulative weight loss vs time,

\section{RESUlTS AND DiscuSSIONS}

A. Variation of slurry velocity or flow rate and different impact angles for the erosion discussed as-

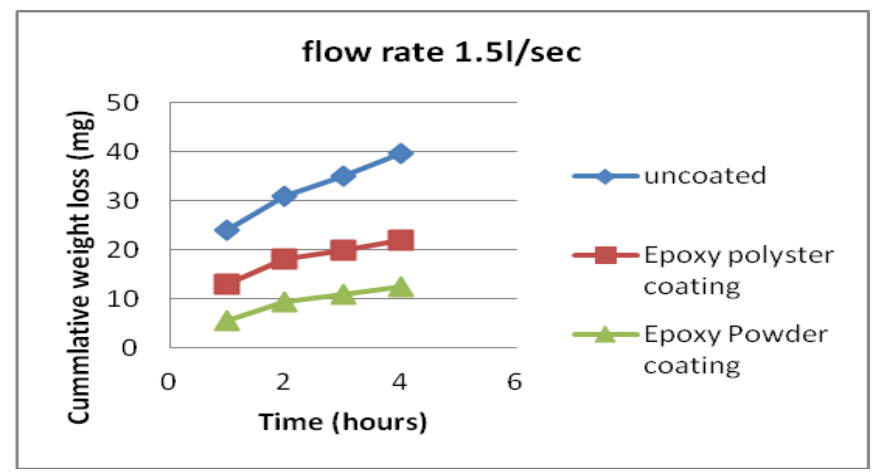

Figure 3 Variation in cumulative weight loss with respect to time at $30^{\circ}$ impact angle.

During the experimentation on $18 \mathrm{Cr} 8 \mathrm{Ni}$ with the velocity rate of $1.51 / \mathrm{sec}$ epoxy powder coating shows higher resistance against erosional wear during the experimentation period for interval of each 1 hour, epoxy powder coating shows increased erosion wear as compared to epoxy polyester and uncoated $18 \mathrm{Cr} 8 \mathrm{Ni}$ metal base with the minimum weight loss of $12 \mathrm{mg}$ in experimentation work of 4 hours.

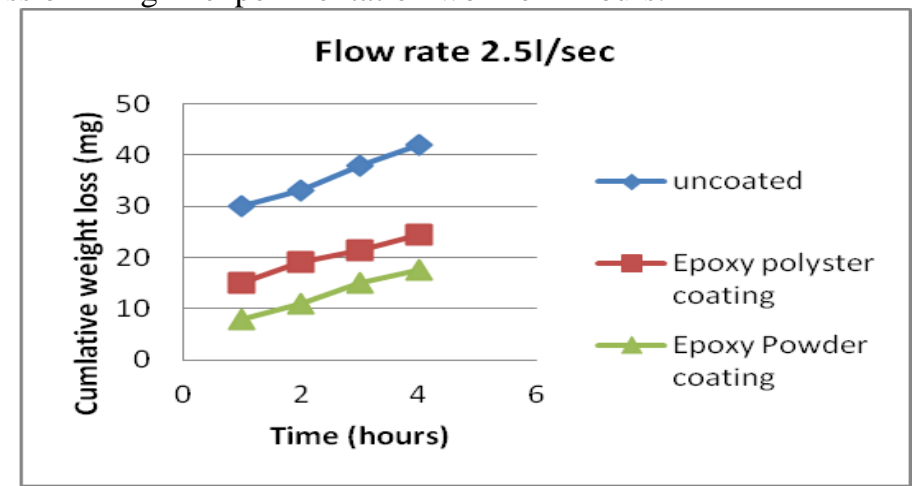

Figure 4 Variation in cumulative weight loss with respect to time at $30^{\circ}$ impact angle.

During the experimentation on $18 \mathrm{Cr} 8 \mathrm{Ni}$ with the velocity rate of $2.51 / \mathrm{sec}$ with an striking angle of 30 degrees there is a increased in metal loss is observed with increased velocity rate. During the experimentation work in first two hours there is loss of $7 \mathrm{mg}$ of metal in epoxy powder coating whereas as this loss of metal is higher in epoxy polyester coating about $15 \mathrm{mg}$. While the loss of metal in uncoated metal strips of $18 \mathrm{Cr} 8 \mathrm{Ni}$ is about 30 mg.

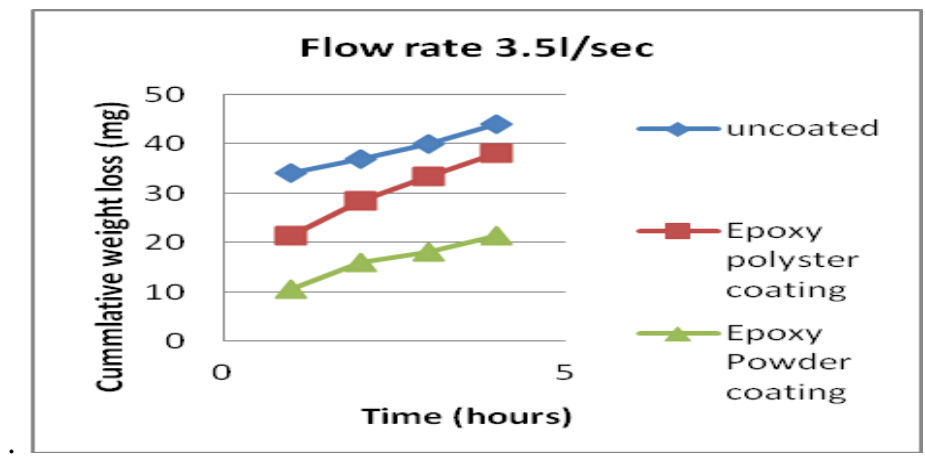

Figure 5 Variation in cumulative weight loss with respect to time at $30^{\circ}$ impact angle. 
In the third factor with varying the flow rate with velocity of 3.51/s with keeping the same angle of striking the resistance epoxy powder is much higher as compared to the epoxy polyester coating. During the experimentation duration of 4 hours the loss of metal in epoxy powder coating is of $20 \mathrm{mg}$ while the readings for epoxy polyester and un-coated strip of $18 \mathrm{Cr} 8 \mathrm{Ni}$ metal strip is $38 \mathrm{mg}$ and $44 \mathrm{mg}$.

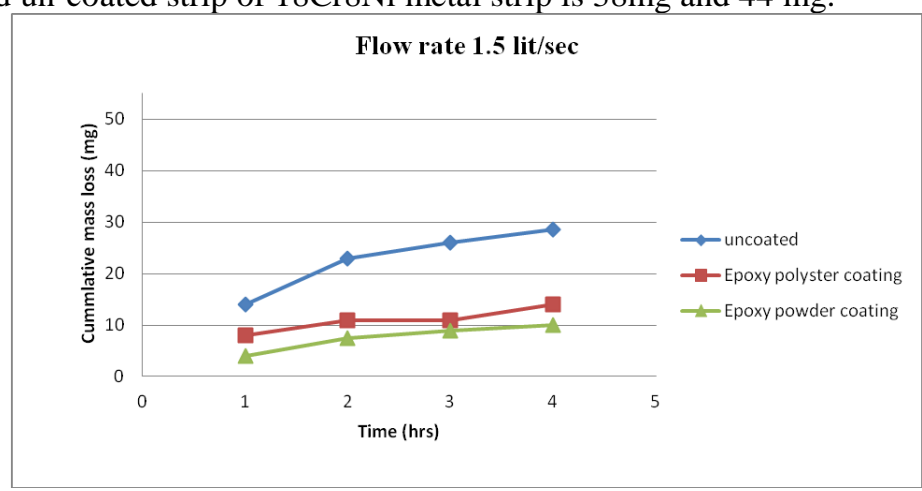

Figure 6 Variation in cumulative weight loss with respect to time at $60^{\circ}$ impact angle

During the experimentation on $18 \mathrm{Cr} 8 \mathrm{Ni}$ with the $1.51 / \mathrm{sec}$ epoxy powder coating shows higher resistance against erosional wear during the experimentation work of gap of each of 1 hour epoxy powder coating shows increased erosion wear as compared to epoxy polyester and uncoated $18 \mathrm{Cr} 8 \mathrm{Ni}$ metal base with the minimum weight loss of $9.5 \mathrm{mg}$ during experimentation work of 4 hours. At lower angles, the effect of bond strength of coating is more than at normal angles. A slight decrease in weight loss is observed when angle is changed from $30^{\circ}$ to $60^{\circ}$. The variations in cumulative weight loss with respect to time at different impact angles and flow rate are shown in figures from 3 to 12 .

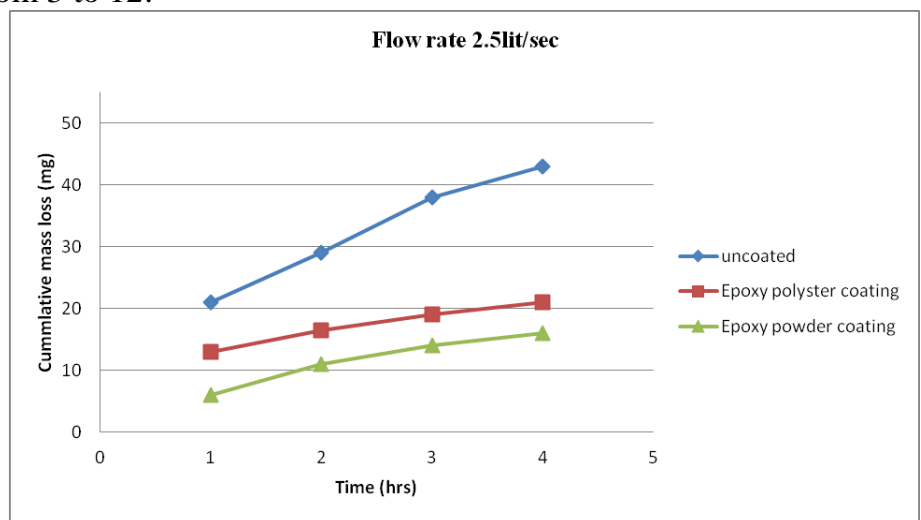

Figure 7 Variation in cumulative weight loss with respect to time at $60^{\circ}$ impact angle

During the experimentation on $18 \mathrm{Cr} 8 \mathrm{Ni}$ with the velocity rate of $2.51 / \mathrm{sec}$ with an striking angle of 60 degrees there is a increased in metal loss is observed with increased velocity rate. During the experimentation work in first two hours there is loss of $5 \mathrm{mg}$ of metal in epoxy powder coating whereas as this loss of metal is higher in epoxy polyester coating about $12 \mathrm{mg}$. While the loss of metal in uncoated metal strip of $18 \mathrm{Cr} 8 \mathrm{Ni}$ is about 21 mg.

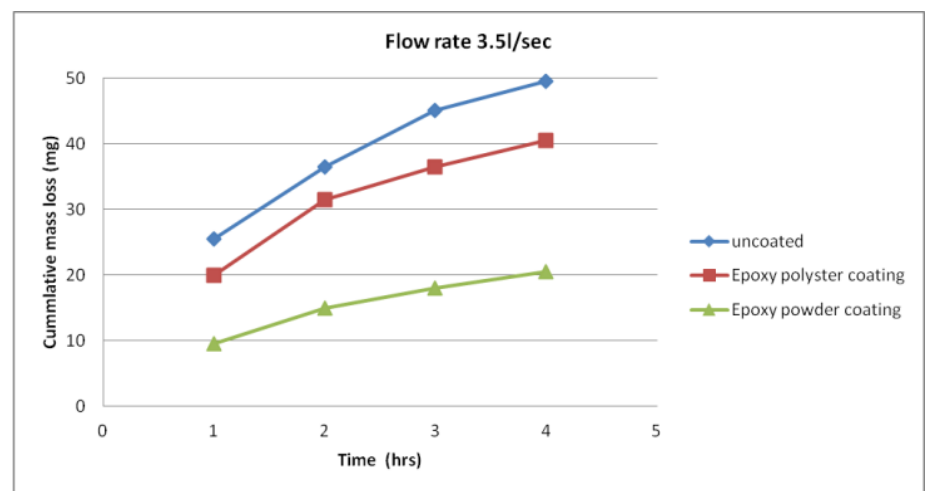

Figure 8 Variation in cumulative weight loss with respect to time at $60^{\circ}$ impact angle 
In the third factor with velocity rate of 3.51/s with same angle of striking the resistance of epoxy powder is much higher as compared to the epoxy polyester coating. During the experimentation of duration of 4 hours the loss of metal in epoxy powder coating is of $20 \mathrm{mg}$ while the readings for epoxy polyester and un-coated strip of $18 \mathrm{Cr} 8 \mathrm{Ni}$ metal strip is $40 \mathrm{mg}$ and $48 \mathrm{mg}$. At lower angles, the effect of bond strength of coating is more than at normal angles

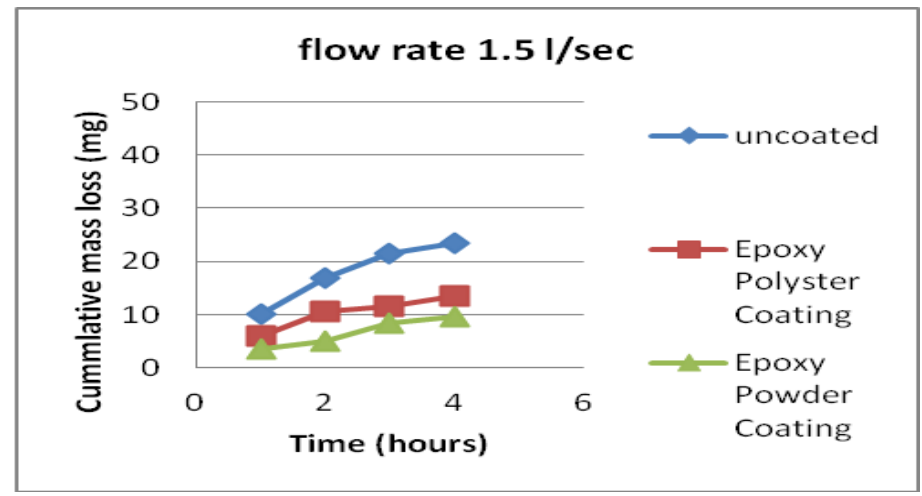

Figure 9 Variation in cumulative weight loss with respect to time at $90^{\circ}$ impact angle

During the experimentation on $18 \mathrm{Cr} 8 \mathrm{Ni}$ with the $1.51 / \mathrm{sec}$ epoxy powder coating shows higher resistance against erosional wear during the experimentation work of gap of each of 1 hour epoxy powder coating shows increased resistance of erosion wear as compared to epoxy polyester and uncoated $18 \mathrm{Cr} 8 \mathrm{Ni}$ metal base with the minimum weight loss of $9.8 \mathrm{mg}$ during experimentation work of 4 hours.

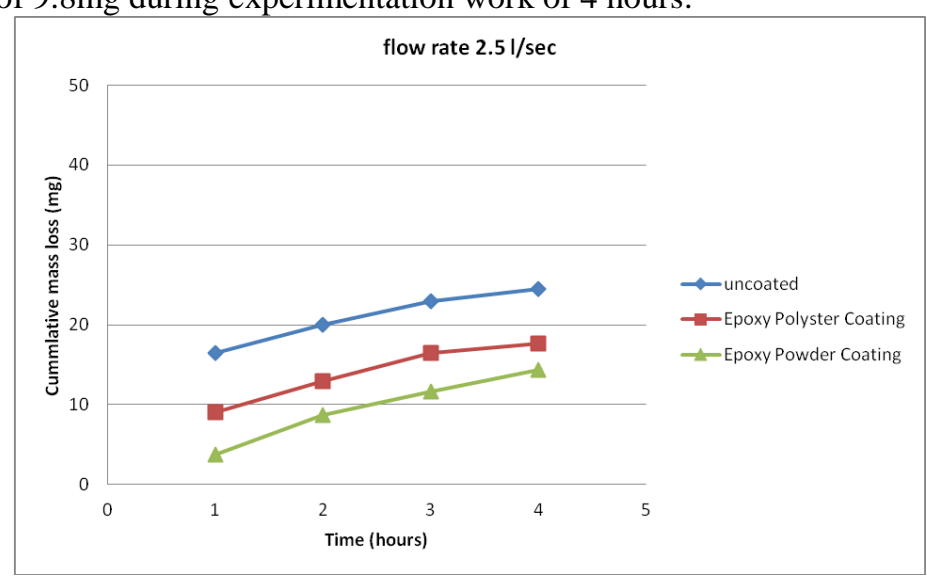

Figure 10 Variation in cumulative weight loss with respect to time at $90^{\circ}$ impact angle

During the experimentation on $18 \mathrm{Cr} 8 \mathrm{Ni}$ with the velocity rate of $2.51 / \mathrm{sec}$ with an striking angle of 90 degrees there is a increased in metal loss is observed with increased velocity rate. During the experimentation work in first two hours there is loss of $14 \mathrm{mg}$ of metal in epoxy powder coating whereas as this loss of metal is higher in epoxy polyester coating about $18 \mathrm{mg}$. While the loss of metal in uncoated metal strip of $18 \mathrm{Cr} 8 \mathrm{Ni}$ is about 25 mg.

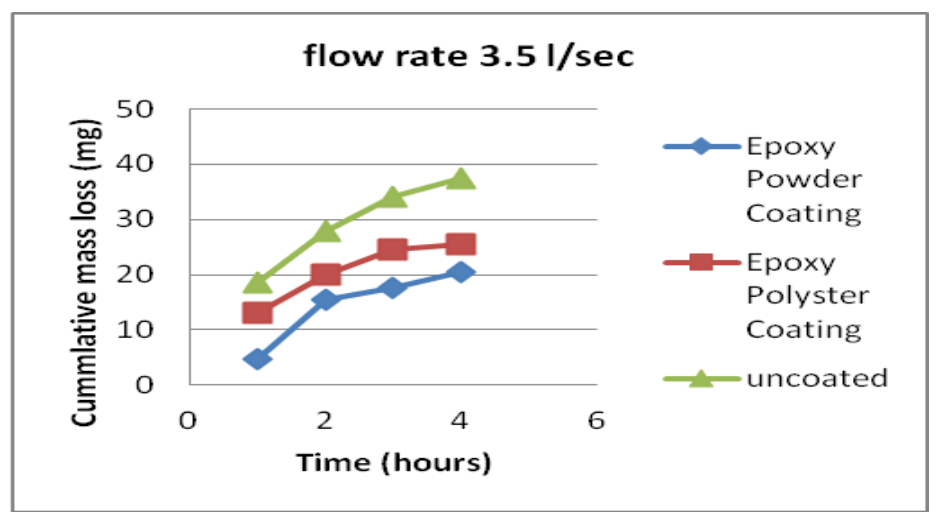

Figure 11 Variation in cumulative weight loss with respect to time at $90^{\circ}$ impact angle 
In the third factor with velocity rate of 3.51/s with same angle of striking the resistance of epoxy powder is much higher as compared to the epoxy polyester coating. During the experimentation of duration of 4 hours the loss of metal in epoxy powder coating is of $20 \mathrm{mg}$ while the readings for epoxy polyester and un-coated strip of $18 \mathrm{Cr} 8 \mathrm{Ni}$ metal strip is $25 \mathrm{mg}$ and $37 \mathrm{mg}$.

\section{EFFECT OF TIME ON EROSION WEAR}

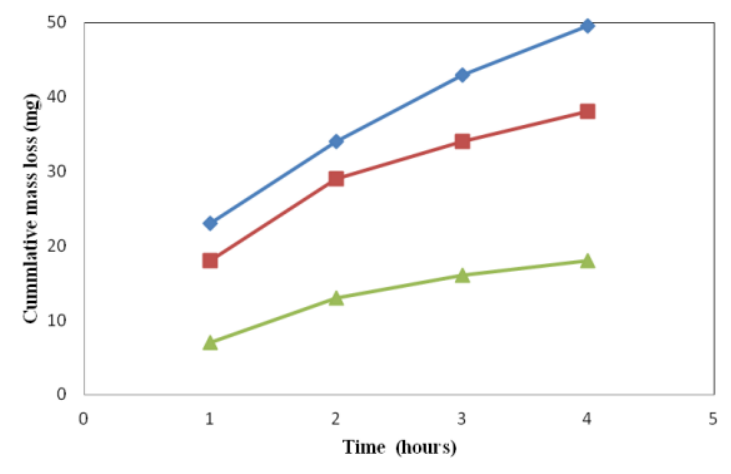

Figure12 Variation in weight loss with respect to time.

The weight loss of uncoated steel is nearly equal in all time intervals and show maximum weight loss. Both coatings shows higher wear initially intervals and then reduction in wear in lateral time intervals. Epoxy Powder coating shows a superior erosion wear resistance than both Epoxy Polyester coated and uncoated steels.

\section{CONClusion}

Coatings of Epoxy Polyester and Epoxy powder using the powder coating method were possible on $18 \mathrm{Cr} 8 \mathrm{Ni}$ steel. During the experimentation work both coatings show better performance than uncoated steel in all conditions in which erosion wear test was performed..Epoxy Powder coating shows the minimum wear as among the other Epoxy Polyester coating and uncoated, $18 \mathrm{Cr} 8 \mathrm{Ni}$ base steel. Maximum erosion wear was reported at $30^{a}$ impact angle and minimum at $90^{\complement}$. Epoxy Powder coated steel shows approximately 3 times better performance than uncoated $18 \mathrm{Cr} 8 \mathrm{Ni}$ steel base. Erosion wear rate with both epoxy polyester and powder coating is observed higher in initial running hours and reduces with respect to time. The erosion of uncoated steel under normal impact is due to platelet mechanism but for coatings under similar condition is due to crack formation.

\section{REFERENCES}

[1] A.P. Harsha, Deepak Kumar Bhaskar Harsha (28 March 2008) "Solid particle erosion behaviour of ferrous and non-ferrous materials and correlation of erosion data with erosion models" Elsevier/Journal.Volume Materials and Design 29, p'p 1745-1754

[2] B.F. LEVIN, K.S. VECCHIO, J.N. DuPONT, and A.R. MARDER (1999) "Modeling Solid-Particle Erosion of Ductile Alloys" Acta Metall. Mater./Journal Volume 38 (7), pp. 1241-54).

[3] Bhupendra K. Gandhi, Satish V. Borse (2003) "Nominal particle size of multi-sized particulate slurries for evaluation of erosion wear and effect of fine particles" Elsevier/Journal Volume 257 ,p'p 73-79

[4] C.G. Telfer,M.M.Stack n, B.D.Jana.(April 2012) "Particle concentration and size effects on the erosion-corrosion of pure metals in aqueous slurries" Tribology International/Journal Volume-53,p'p 35-44.

[5] Deepak Kumar Goyal, Harpreet Singh, Harmesh Kumar, and Varinder Sahni(April 2012) "Slurry Erosive Wear Evaluation of HVOF-Spray Cr2O3 Coating on Some Turbine Steels" ASM International/Journal, Volume- 21,p'p838-851.

[6] Ezddin Ali Farag Hutli - Milos S. Nedeljkovic ·Nenad A. Radovic Aug 2007) "Mechanics of submerged jet cavitating action material properties, exposure time and temperature effects on erosion" Springer-Verlag/Journal, Volume- 78:,p'p 329-341

[7] Girish R. Deale, Bhupendra K. Gandhi, S.C. Jain.(May 2007) "Slurry erosion of ductile materials under normal impact condition" Elsevier/Journal, Volume 264, p’p 322-330

[8] Girish R. Desalea, Bhupendra K. Gandhib, S.C. Jain (Jan 2009) "Particle size effects on the slurry erosion of aluminium alloy".Elssevier/Journal Volume- 266 .p'p 1066-1071

[9] H. Winkelmann Æ M. Varga Æ E. Badisch Æ H. Danninger.(March 2009) "Wear Mechanisms at High Temperatures Part 2 Temperature Effect on Wear Mechanisms in the Erosion Test". Tribol Lett/Journal. Volume- 34, p'p 167-175

[10] J.F. Flores, A. Neville, N. Kapur, and A. Gnanavelu.(Sept 2010) "Corrosion and Erosion-Corrosion Processes of Metal-Matrix Composites in Slurry Conditions”ASM International/Journal. Volume 21. p'p 395-405.

[11] J.M. Guilemany, N. Cinca, J. Ferna'ndez, and S. Sampat Sept 2008) "Erosion, Abrasive, and Friction Wear Behaviour of Iron Aluminised Coatings Sprayed by HVOF " ASM International/Journal . Volume 17.p'p 762-773

[12] K.S. Tan, J.A. Wharton, R.J.K. Wood (2004) "Solid particle erosion-corrosion behaviour of a novel HVOF nickel aluminium bronze coating for marine applications” Elsevier/Journal. Volume-258,p’p 629-640 


\section{AUTHORS}

First Author - Ashraya Gautam, Master's of Techonology (Rayat \& Bahra College Engineering (Mohali140104 ), Mechanical engineering department, India.

Second Author - Charanjit Singh Sandhu,Master's of Techonology(S.U.S.C.E.T TANGORI 140306 Mechanical Engineering Department, SUSCET Tangori),India

Third Author-Harpreet Singh Randhawa, Master's of Technology (Rayat \& Bahra College Engineering (Mohali-140104), Mechanical engineering department, India.

Fourth Author-Navjot Singh, Master's of Technology (Sri Sukhmani Institute of Engineering \& Techonology Derabassi 140507 ), Mechanical engineering department, India.

Correspondence Author - - Ashraya Gautam, Master's of Techonology (Rayat \& Bahra College Engineering (Mohali-140104), Mechanical engineering department, India. 